\title{
Normal Ventricular Ejection Fraction
}

National Cancer Institute

\section{Source}

National Cancer Institute. Normal Ventricular Ejection Fraction. NCI Thesaurus. Code C99513.

The usual amount of blood that is forced from the heart ventricle to produce cardiac output. Quantitatively, the ejection fraction is considered between $50 \%$ to $70 \%$. 